\title{
Pedagogía hermenéutica del lugar: estudio narrativo sobre la relación entre lugaridad, alteridad, ciudad y escuela
}

Hermeneutic pedagogy of place: narrative research about relationship among, Placeness,

Otherness, City and School

\section{Volumen 17, Número 2}

Mayo-Agosto

pp. 1-34

Este número se publica el $1^{\circ}$ de mayo de 2017

DOI: http://dx.doi.org/10.15517/aie.v17i2.28729

Rodrigo Moreno Aponte

Revista indizada en REDALYC, $\underline{\text { SCIELO }}$

Revista distribuida en las bases de datos:

LATINDEX, DOAJ, REDIB, IRESIE, CLASE, DIALNET, SHERPA/ROMEO, QUALIS-CAPES, MIAR

Revista registrada en los directorios:

ULRICH'S, REDIE, RINACE, OEI, MAESTROTECA, PREAL, CLACSO 


\title{
Pedagogía hermenéutica del lugar: estudio narrativo sobre la relación entre lugaridad, alteridad, ciudad y escuela
}

Hermeneutic pedagogy of place: narrative research about relationship among, placeness, otherness, city and school

\section{Rodrigo Moreno Aponte ${ }^{1}$}

Resumen: Este artículo presenta los resultados del estudio que se realizó en el Colegio Distrital ubicado en Bogotá, Colombia. Se aplicó el método biográfico-narrativo para indagar sobre el espacio vivido de la ciudad y la escuela. El foco fueron cinco relatos de vida de dos docentes y tres estudiantes. La interpretación de los resultados se hizo desde el enfoque fenomenológico-hermenéutico para hallar el sentido de la siguiente pregunta de investigación: ¿Cuál es la naturaleza de la relación entre los lugares vividos del estudiante fuera de la escuela urbana, en los que se desarrollan manifestaciones culturales e ideológicas, y las dinámicas de su interior, que permitan proponer situaciones de alteridad por medio de una pedagogía hermenéutica del lugar? Los resultados arrojaron una idea esencial que consiste en que los espacios de la ciudad y de la escuela deben vincularse para fortalecer los procesos de alteridad. Consecuentemente, una pedagogía hermenéutica del lugar se presenta como una acción educativa que permite reconocer las diferencias culturales de los sujetos que exige la sociedad.

Palabras clave: investigación pedagógica, escuela, lugaridad, alteridad, hermenéutica, educación

\begin{abstract}
This article presents the research results of the study that took place in a public school located in Bogotá, Colombia. A narrative-biographical method was applied to look into the city and school lived space. It was focused on 5 life stories of two teachers and three students. The result's interpretation was done from the phenomenological hermeneutic approach, to find the sense of this research question: What is the quality in the connection between the student lived places out of school, where cultural and ideological expressions are developed, and the dynamics within, which allow to propose otherness situations through an hermeneutic pedagogy of the lived place? The results bring an essential idea which is to connect spaces in the city and at the school to strengthen processes of otherness. As a consequence, a hermeneutic pedagogy of place is presented as an educational action which allows to recognize the cultural differences of subjects that our society demand.
\end{abstract}

Key words: pedagogical research, school, placeness, otherness, hermeneutic, education

\footnotetext{
1 Docente en departamento de pedagogía de la Facultad de Educación, Corporación Universitaria Minuto de Dios, Bogotá Colombia. Doctor en Educación y Comunicación Social de la Universidad de Málaga, España.
}

Dirección electrónica: rodrigo.moreno81@yahoo.com

Artículo recibido: 28 de mayo, 2016

Enviado a corrección: 3 de marzo, 2017

Aprobado: 25 de abril, 2017 


\section{Introducción}

La preocupación que convoca esta investigación es el espacio como configurador de las relaciones sociales entre la ciudad y la escuela. Compartimos la idea de Lefebvre (2013) en la que "el concepto de espacio (social) y el espacio mismo escapan a la clasificación «baseestructura- superestructura»" (p. 56). Si pensamos el espacio como un producto social, entonces:

Él mismo es el resultado de la acción social, de las prácticas, las relaciones, las experiencias sociales, pero a su vez es parte de ellas. Es soporte, pero también es campo de acción. No hay relaciones sociales sin espacio, de igual modo que no hay espacio sin relaciones sociales. (Martínez, 2013, p. 14)

Lefebvre reconoce como tautológica la afirmación: "El espacio (social) es un producto (social)" (Lefebvre, 2013, p. 86). Por esto mismo se puede afirmar que esta es una relación evidente, puesto que el espacio social es el núcleo de relaciones entre las significaciones de las personas que lo habitan, no es el espacio de planetas o cuerpos celestes sin vida, sino el espacio constituido por humanos con cúmulos de experiencias, que piensan algo del espacio, los que configuran estas relaciones.

[...] [E]s posible hablar de dos tipos de espacio: por un lado, un espacio objetivo, equivalente al infinito indiferenciado de las coordenadas cartesianas, cuya característica principal es la extensión. Por el otro, un espacio habitado, lleno de significaciones, puntos de vista, perspectivas, distancias, cercanías y relaciones, un espacio creado intersubjetivamente. (Pérez y Núñez, 2008, p. 18)

Para explicar de una forma más concreta lo que nos planteamos en esta investigación, en la que se tiene como base el espacio social, nos centramos en el análisis del espacio de la escuela urbana. Esto no supone que nos anclamos a un análisis desde el interior de la institución escolar, más bien, se busca comprender su relación con la ciudad. Por ende, nos situamos en el estudio de la escuela urbana. De aquí subyacen dos conceptos claves para esta investigación: Lugaridad y Alteridad.

Pretendemos que esta investigación fundamente, a futuro, un tipo de pedagogía que acoja la relación entre los conceptos nombrados, a saber: Espacio social de la ciudad-escuela 
urbana-lugaridad-alteridad. A esta manera de ver la acción educativa la llamamos Pedagogía Hermenéutica del Lugar.

Quisimos acceder a la investigación desde la siguiente pregunta: ¿Cuál es la naturaleza de la relación entre los lugares vividos del estudiante fuera de la escuela urbana, en los que se desarrollan manifestaciones culturales e ideológicas, y las dinámicas de su interior, que permitan proponer situaciones de alteridad por medio de una pedagogía hermenéutica del lugar?

La anterior pregunta nos llevó a establecer como objetivo general el siguiente: Indagar la experiencia vivida del estudiante a partir de la relación entre sus manifestaciones culturales y la escuela para interpretar el camino hacia el desarrollo de la alteridad por medio de una pedagogía hermenéutica del lugar. En consecuencia, se desprenden tres objetivos específicos. En primer lugar, se busca comprender las experiencias de estudiantes que hacen parte de una cultura urbana que no está vinculada a la cultura adultocéntrica de la sociedad, y que no es reconocida por las pretensiones disciplinarías que pueda tener la escuela. En segundo lugar, como consecuencia de lo anterior, se pretende relacionar el lugar vivido de los estudiantes fuera de la escuela con el interior de esta institución. Finalmente, con respecto al momento empírico de la investigación, se quiere realizar un acercamiento desde una propuesta fenomenológico-hermenéutica para acceder al fenómeno de la acción educativa propuesto para esta investigación.

De acuerdo con lo anterior, el orden que sigue para este artículo será el siguiente: En principio, en el marco teórico, ahondaremos en la forma cómo entendemos los conceptos de ciudad, lugaridad, alteridad y pedagogía hermenéutica del lugar. En segundo lugar, exponemos las generalidades de la metodología fenomenológico-hermenéutica y los puntos del método que nos permiten interpretar los resultados. Después de esto, presentamos los resultados del proceso interpretativo. Por último, puntualizamos las consideraciones finales propias de esta investigación.

\section{Referentes teóricos}

\subsection{El espacio de la ciudad}

Pretendemos comprender la ciudad como la complejidad de lo múltiple. Para esto, acudimos a la propuesta de Hiernaux (2006) con respecto a la experiencia del espacio urbano desde una perspectiva ontológica, a saber: La ciudad laberíntica, la ciudad fugaz y la ciudad 
fortuita. La primera sugiere un espacio en el que tenemos una experiencia confusa de la ciudad debido a la complejidad de los lugares de paso que la transforman en una red de caminos que lleva a movimientos de ida, vuelta, retroceso y avance. La segunda ciudad es fugaz porque, debido al afán que depara la vida cotidiana, no tenemos tiempo para disfrutarla o tener una experiencia contemplativa de ella. La tercera ciudad, la fortuita, se manifiesta por medio del encuentro de realidades diferentes en su interior en el que, al vincularse entre sí, surgen situaciones nuevas, en muchos casos, inesperadas. Por lo tanto, encontramos que hay distintos espacios urbanos del mismo espacio de la ciudad. Lo anterior significa que este tipo de espacio, más allá de ser una cuestión localizable en un mapa, es un entramado de relaciones complejas que evidencian la experiencia del que habita ahí.

\subsection{Apropiaciones espaciales: la cuestión del lugar}

La relación particular del sujeto con el espacio de la ciudad pasa por el concepto de habitus. El hábitat es un espacio, si se quiere, en el que se convive, pero se convierte en habitus cuando empiezan a cobrar significado las relaciones sociales o los intereses particulares independientes de otros (Bourdieau, 2007).

Por otra parte, Heidegger (2010) plantea, desde una propuesta ontológica, que el espacio empieza a cobrar un significado más allá de un simple estar-ahí. El filósofo alemán acude a constituir como verbo el sustantivo espacio, es decir, el espacio es espaciar. El acontecimiento espacial se da por medio del emplazamiento que abre la relación entre las cosas en el espacio. En consecuencia, sale a la luz el concepto de lugar. El espacio es espacio cuando se torna en lugar. A mayor importancia del espacio para el sujeto, se da paso a la percepción del lugar.

Para explicar el concepto de lugar, tenemos presente cómo Gastón Bachelard (2005), desde una descripción fenomenológica relacionada a las representaciones poéticas, busca señalar las imágenes del espacio que producen felicidad. El sentimiento que estas despiertan las define como un estado que lleva a la topofilia, que, a grandes rasgos, sería la relación de amor o afecto con los espacios que son significativos. Este es el espacio que no nos es indiferente en lo absoluto. Es un espacio que "[e]s vivido. $Y$ es vivido, no en su positividad, sino con todas las parcialidades de la imaginación. En particular, atrae casi siempre" (Bachelard, 2005, p. 22). 
Yi-Fu Tuan (2007) lleva el concepto de topofilia a la geografía humana. Desde ahí sostiene la idea de la existencia de la relación de intimidad entre el sujeto y el lugar. Es un espacio, no por el que se transita, sino por el que se vive una situación que es significativa para el sujeto. El espacio no es una cosa que se presenta para nuestra instrumentalización, más bien, es para que sea vivido como lugar.

Es por medio de la experiencia del habitus del espacio como se da paso al concepto del lugar. Son espacios significativos para el sujeto. No pasan desapercibidos. En este sentido se pueden relacionar tres principios (Massey, 2005) que sostienen que la situación de la experiencia espacial del sujeto lleva implícita consigo la apropiación como lugar: 1. El espacio es producto de interrelaciones 2. El espacio es la esfera de la posibilidad de la existencia de la multiplicidad 3. El espacio nunca es acabado, siempre está en proceso de formación.

Por consiguiente, se evidencia que el lugar no es estático, ni es fruto de parcelamientos del espacio, mucho menos desarrolla identidades únicas para los sujetos. El lugar no es específico, sino que se reproduce continuamente.

\subsection{Heterotopía y no lugar}

Ante este panorama de complejidad del espacio urbano y su relación inherente con la experiencia de los sujetos, consideramos pertinente dirigir nuestra mirada al término de heterotopía (Foucault, 1999). Este se refiere a espacios con discursos o simbologías opuestas, pero que, a su vez, están yuxtapuestos. Por ejemplo, un centro comercial que se encuentra a pocos metros de un barrio en condición de pobreza, o una cárcel contigua a un colegio. Estos espacios también presentan la dinámica de estar constituidos a partir de encerramientos que se aíslan entre sí. No obstante, proponemos la figura topológica de la cinta de möbius para explicar que la dinámica del sujeto en la ciudad es la de entrar y salir simultáneamente de estos espacios que se contradicen entre sí, a pesar de que estén diferenciados uno del otro por medio de encerramientos.

Esta experiencia heterotópica que el sujeto tiene de la ciudad, la vinculamos con el concepto de no-lugar (Augé, 2000, 2004), a saber: una experiencia de espacio que se invisibiliza o sencillamente no guarda un significado social para el sujeto. Sin embargo, se apoya la idea de que estos no-lugares producen individuos así como la heterotopía. Por esto último, estos conceptos, esencialmente espaciales, nos llevan a una comprensión más particular de la ciudad. 
Para resumir, la espacialidad del espacio se halla en relación con lo humano. El espacio está en todo lado, pero somos nosotros los que le damos su significado. Sumado a esto, notamos la preeminencia de la lugaridad del lugar en la conformación de la identidad del sujeto.

Somos, tal vez, como producto social un vehículo de etiquetas, marcas. Lo que somos tiene un marcaje de lugaridad, que nos hace ser lo que creemos ser y lo que los otros creen que somos; lugaridad como contexto simbólico pensado-sentido-vivido, producido desde la interpretación colectiva de las historias culturales que definen imágenes identitarias plurales y diversas. (Vásquez y Pérez, 2009, p. 654)

\subsection{La constitución espacial de la escuela urbana}

A la luz de lo anterior, tenemos en cuenta que la situación de la escuela urbana constituye la dinámica entre los discursos que se dan en su interior y su exterior, que, a su vez, producen dos acontecimientos: la escuela como límite y la escuela como frontera.

Simmel desarrolla el concepto de límite al compararlo con el marco de una obra de arte. Este cumple la función de diferenciar la obra de sus puntos adyacentes, y a la vez, se la encierra en sí misma. Acá se fortalecen las características de la obra de arte.

Igualmente una sociedad se caracteriza como interiormente unida, cuando el espacio de su existencia está limitado por límite perfectamente claros, y al contrario: la unidad mutua, la relación funcional de todos los elementos entre sí, se expresa espacialmente por el límite que sirve de marco. (Simmel, 1927, p. 17)

La consecuencia del límite, desde una perspectiva sociológica, es que genera una división entre las partes que se repelen y ejercen acciones "ofensivas" y "defensivas" entre dos vecinos. Cuando se propone la escuela desde un lugar de límites, el estudiante entra en contradicción con su mundo vital, pues él se tiene que desentender de las dinámicas del exterior en las que también configura su identidad, para, desde ahí, ingresar al espacio cerrado de la escuela. Aquí el estudiante queda transitando entre espacios que se repelen.

La frontera, por otra parte, maneja relaciones con el exterior. Acá sí se necesita del otro. Mientras que al límite no le interesa el exterior, a la frontera sí. "Las fronteras cumplen con una función dual de ser barreras y membranas permeables a la vez" (Giroux, 1997, p. 36). Las fronteras son de origen social, no son generadas a partir de coordenadas abstractas. 
Hacer referencia a la frontera significa establecer vínculos entre dos o más actores. Asumir las prácticas pedagógicas en el sentido de una frontera nos permite, como educadores, entender la posibilidad de reconocer manifestaciones culturales distintas a la propia, o la que impera en la sociedad.

\subsection{Pedagogía de la alteridad}

La alteridad la entendemos desde la filosofía de Levinas (1993, 2000, 2001, 2002, 2003) que, de manera muy general, se define como la responsabilidad que tengo hacia el otro a partir de una exterioridad que se me aparece en torno a una relación ética ${ }^{2}$. Estas ideas son recogidas por la Pedagogía de la alteridad (Bárcena y Mèlich, 2000; Larrosa y Skliar, 2009; Magendzo, 2006; Mèlich, 1994; Ortega, 2004; Skliar, 2002; Valera-Villegas, 2002; Vila, 2005). Esta corriente pedagógica pone en el plano de la acción educativa las relaciones éticas que se dan en la escuela. De ahí que se encuentre el interés, que en la actualidad cobra relevancia, por la convivencia desde relaciones de respeto y tolerancia entre los unos con los otros.

\subsection{Pedagogía hermenéutica del lugar}

El reconocimiento de la experiencia del lugar de los estudiantes nos permite encontrar otra vía de acceso hacia la alteridad en la acción educativa en la escuela. La relación pedagógica, que tiene como fondo la alteridad en la escuela, se relaciona con lo que nos dejan los conceptos espaciales en la relación escuela-ciudad. Para esto, anclamos la idea central de esta investigación en la propuesta de una Pedagogía hermenéutica del lugar.

Nuestra propuesta pedagógica propone la comprensión de los lugares de los estudiantes por medio de la interpretación de su lugaridad. Esto implica la necesidad de que los sujetos que orientan los procesos pedagógicos en las instituciones escolares se descentren de su propia experiencia cultural para poder acceder a la experiencia espacial de los estudiantes (Skliar 2002, 2006). Por lo tanto, es necesaria una oposición a un pensamiento pedagógico que considere la realidad como una totalidad acabada que debe seguirse a partir de una tradición cultural establecida en la que poco importan las manifestaciones culturales

\footnotetext{
${ }^{2}$ No obstante, consideramos que es en la propuesta de Paul Ricoeur (2006) en la que se halla una idea más apropiada para el tipo de alteridad que buscamos, esto es, el reconocimiento en el que hay una reciprocidad en el acto de acoger al otro.
} 
minoritarias. Todo esto compone la necesidad de que haya una relación pedagógica atravesada por las relaciones de alteridad.

El tipo de pedagogía que planteamos es hermenéutica porque busca la comprensión e interpretación del otro a partir del vínculo con el lenguaje (Gadamer 1992, 2003). Nos referimos al lenguaje que posibilita el diálogo. Este es un estado de apertura hacia el otro, por medio de la escucha para poder intervenir con la palabra y que esta pueda ser devuelta. Es una pedagogía del lugar porque toma en cuenta los lugares en los que los estudiantes y las estudiantes desarrollan su identidad. Por lo tanto, lo que se encuentra acá es una relación pedagógica desde el vínculo entre alteridad, lenguaje y lugaridad.

\section{Metodología}

La investigación se realizó en el Colegio Distrital ${ }^{3}$, de carácter público, ubicado en Bogotá, Colombia. Los participantes de la investigación fueron dos jóvenes mujeres de 16 y 17 años, un joven hombre de 17 años, y dos docentes hombres adultos de la institución.

Para acceder a la comprensión del fenómeno que nos planteamos para esta investigación acudimos al método biográfico-narrativo (Bolívar, 2002a, 2002b; Bolívar y Domingo, 2006; Bolívar, Domingo y Fernández (2001); Bolívar y Porta 2010; Conelly y Clandinin, 1986), particularmente a los relatos de vida por medio de entrevistas a profundidad. Entendemos por narración

La cualidad estructurada de la experiencia entendida y vista como un relato; por otro (como enfoque de investigación), las pautas y formas de construir sentido, a partir de acciones temporales personales, por medio de la descripción y análisis de los datos biográficos. (Bolívar, 2002a, p. 6)

Las narraciones, al ser textos que parten de una experiencia directa con el mundo que compartimos, requieren por parte del investigador un estado en el que se permita el diálogo con la experiencia que se interpreta; por lo tanto, se tiene presente que no estamos frente a un dato, sino a un cúmulo de significaciones del mundo de la vida cotidiana (Schütz 1972, 1974). Además, la interpretación debe partir de la relación entre el contexto, lector y texto (Gadamer, 1992, 2003), así como de la estructura narrativa que muestra el cumulo de vivencias del sujeto (Ricoeur 1993, 1999, 2000, 2002, 2004).

\footnotetext{
${ }^{3}$ En la negociación con la institución y los participantes, se llegó al acuerdo de que los nombres serían cambiados.
} 
El informe narrativo, que surge de la interpretación de los relatos de vida de los participantes, tiene como base la interpretación fenomenológico-hermenéutica. Se tuvieron en cuenta los siguientes puntos de análisis (Van Manen, 2003):

- La aproximación holística o sentenciosa: Lo que se busca con esto es identificar una frase sentenciosa que capte el significado esencial de la narrativa.

- La aproximación selectiva o de marcaje: dentro de la estructura narrativa se identifican una serie de frases que den cuenta del contenido esencial que se busca comprender.

- La aproximación detallada línea a línea: Se aferra frase por frase, estrictamente para hallar el tema esencial.

Asimismo, se usaron variaciones imaginativas para sacar a la luz la esencia del problema. A su vez, se establecieron las coordenadas vivenciales que se encuentran en las experiencias de cada uno de los participantes de la investigación. Por consiguiente, surgieron gráficas que sirvieron para ilustrar espacialmente la interpretación de la experiencia vivida de cada uno de los participantes.

Para fortalecer la fiabilidad de la investigación se realizó una triangulación entre los diarios de campo surgidos de las observaciones en el Colegio Distrital, los referentes teóricos y la interpretación de las narrativas. Igualmente, se elaboró una triangulación entre sujetos, ya que, aunque se tiene en cuenta que las narraciones son una experiencia particular, estas se cruzan cuando tienen una experiencia del mismo espacio. Si bien los participantes comparten el espacio del colegio, no es la misma experiencia de ese espacio.

\subsection{La negociación}

Se pidieron los permisos correspondientes al Colegio Distrital para realizar la investigación en su espacio. Por otro lado, se solicitó la aprobación escrita de los padres para que sus hijos, menores de edad, pudieran ser entrevistados y grabados. Con los participantes foco de las narrativas se llegó al acuerdo de la estructura, límites y alcances de las entrevistas. Se acordó con cada participante el compromiso de que, a medida que iban surgiendo las narraciones, serían informados acerca del proceso y, además, se les garantizó el anonimato. 


\section{Interpretación de los resultados: Narrativas de lugaridad y alteridad}

\subsection{Eduardo: Coordenadas de alteridad}

Eduardo es un amante de la música rock, lo cual, de por sí, ya lo diferencia de la mayoría de docentes del colegio, puesto que ellos y ellas no son afines a este género musical. "(...) en mi juventud empecé a ir a muchos toques de rock, de punk, de ska, y pues uno empieza a interactuar con estos rude boy, con estos punkeros pues uno empezaba a escuchar carretas de la vida más interesantes, más humanas" (Eduardo).

Su experiencia con el rock le ayudó a enfocarse en la docencia, pues, para él, por medio del conocimiento se puede hacer un cambio positivo en las personas. "Mi filosofía de vida es que todo ser humano, todo lo que hace en la vida es para ser feliz. Ese es como el objetivo principal, hacer lo que me gusta, y hacerlo bien, sin dañar a nadie, sin que mi forma de pensar dañe a nadie" (Eduardo). Acá se encuentra un indicio de alteridad en Eduardo, pues está teniendo en cuenta sus acciones en relación con los demás. Esto se confirma cuando expresa lo siguiente, con respecto al significado que él le da a al concepto de libertad: "defender sus derechos y yo defiendo los míos, siempre y cuando los suyos no me ataquen" (Eduardo). El tener claro este concepto de libertad le permite a Eduardo acercarse a los estudiantes y las estudiantes. Pero este acercamiento, partiendo de su premisa de no afectar de manera negativa a los demás, supone unos límites tácitos en su forma de actuar como docente. Esto le permite que la relación se dé en el marco del respeto mutuo.

En uno de los encuentros con Eduardo se le pregunta directamente la razón por la cual él considera que es reconocido por la comunidad estudiantil como uno de los docentes que más aprecian. Su respuesta es la siguiente:

Una de las cosas que me acerca a las pelaos ${ }^{4}$ es que me gusta mi trabajo; segundo, con los pelaos hablo como yo hablo. O sea, nunca me expreso como "joven", "oye señorita" una vaina ${ }^{5}$ así, pues eso como que no va conmigo. Yo creo que el vocabulario hace una gran diferencia con los estudiantes. Más que todo yo le digo a los estudiantes "ey parce ${ }^{6}$ hágame un cruce 7 ", "ey viejo, estamos en clase", si el pelao está en clase con

\footnotetext{
${ }^{4}$ En lo que sigue trataremos de explicar el significado de algunas palabras que pueden ser propias del dialecto de los habitantes de la ciudad de Bogotá. En este caso, Eduardo usa la muletilla, "pelao", para referirse a los jóvenes en general.

${ }^{5}$ La palabra vaina se usa para referirse a una cosa o situación en particular.

${ }^{6}$ Esta palabra se usa para referirse de una manera más cercana a un semejante.

${ }^{7}$ En este contexto significa hacer un favor.
} 
un celular le digo como "oiga guarde esa panela8" Entonces los pelaos se dan cuenta que como que hay una igualdad de condiciones en la que estamos, lo que le digo, es una transacción entre parces. Los pelaos copian ${ }^{9}$ a eso. (Eduardo).

Encontramos entonces varias claves frente a las razones por las que este docente despierta una fuerte empatía con el grupo de estudiantes:

1. Lenguaje: El uso del lenguaje para Eduardo es algo que hace parte de su trabajo. No cambia su forma de hablar cuando él se dirige al colectivo de jóvenes, y él es consciente de esto.

2. Instrucción: El lenguaje que usa Eduardo con los estudiantes y las estudiantes le permite, más allá de tener un trato cercano, que sigan las instrucciones que él les sugiere. Ellos y ellas no se sienten vulnerados, por lo contrario, lo hacen con gusto porque no es una imposición.

3. Transacción: La transacción acá hay que verla no desde el plano comercial, sino desde el trato, el convenio. Lo que se acuerda entre las partes es que están en igualdad de condiciones, pero por esto mismo, si ellos y ellas quieren recibir un buen trato, tienen que darlo. Es una colaboración entre dos partes. No es una obediencia de un lado al otro $^{10}$.

El vínculo que se pone en evidencia en el relato de Eduardo es entre lenguaje, instrucción y transacción. Pero, como se puede ver, la situación parte de un lenguaje en el que el grupo estudiantil se siente identificados e incluido. Al respecto, Eduardo dice lo siguiente:

Es que al mismo tiempo esa relación cercana hace que ellos mismos tengan esas mismas reglas. Con el profe bien, pero también hay una barrera que yo no cruzo, y yo

\footnotetext{
${ }^{8}$ Comestible dulce de forma rectangular.

${ }^{9}$ Se refiere a que siguen la idea que él propone.

10 De ninguna manera la interpretación puede dar a entender que Eduardo, por el hecho de ser reconocido por los estudiantes por su buen trato, sea un mejor o peor docente en este colegio. Una postura maniquea de las experiencias de la relación de los docentes con los estudiantes, sugiere un defecto de la comprensión del fenómeno educativo. Seguramente existirán docentes con gustos y experiencias similares a los de Eduardo, que no necesariamente se vinculen con los estudiantes de la manera que este docente lo hace. Lo que ocurre es que, en este relato de vida particular, encontramos una coherencia entre la experiencia previa de Eduardo y su forma de relacionarse con los estudiantes. Dicho esto, insistimos en el hecho de que el sentido de la pregunta de la investigación no surge a raíz de las ideologías o juventud, sino que la esencia del fenómeno educativo que pretendemos comprender se halla en el momento de la relación directa entre docente-estudiante.
} 
tampoco con ellos. Entonces es como usar la naturalidad de ser yo mismo, sin tener que fingir algo que no soy, ni seguir unas reglas con las que no estoy de acuerdo, sino reconocer a cada uno de los pelaos. (Eduardo).

Encontramos un movimiento que parte del interés del profesor por acogerlos en su propio lenguaje. Esto genera que la convivencia entre ellos y ellas se afiance sobre la base del respeto. No es un respeto impuesto por el miedo, sino que está formado a partir de la relación social entre iguales: seres humanos.

En el relato de Eduardo hay límites entre las libertades individuales de cada uno. Fue difícil, en este punto de la interpretación, eludir que nos encontrábamos ante una evidencia clara de alteridad. En la frase subrayada, Eduardo pone sobre la mesa uno de los pilares de la alteridad: el reconocimiento del otro. Es saber de ellos y ellas no como grupo, sino a partir de su individualidad.

Con respecto a la presencia de la lugaridad en los relatos de Eduardo, encontramos un evento en el cual él relata los diálogos que tiene con algunos estudiantes acerca de sus experiencias fuera de la escuela: "Cuando uno habla con los pelaos de por qué les gusta, 'no, pues es que hablan de la vivencia de la calle, de los pobres, de la vida, del vicio, de cosas asi'”. Ahí me di cuenta que los pelaos se acercan a cosas relacionadas hacia su mismo ser". (Eduardo).

En esta intervención encontramos tres características esenciales: diálogo, comprensión de los lugares que viven los estudiantes y las estudiantes e interpretación de la experiencia del otro. Eduardo, con el acercamiento por medio de la palabra, busca comprender los lugares que ellos y ellas habitan, en este caso la calle. No obstante, esta no es cualquier calle, es la que se refiere a un desbalance económico (pobreza). Eduardo no se ha relacionado directamente con ese tipo de lugar, pero sí logra hallarle significado por medio de la interpretación a la que logra acceder a través de la palabra de los estudiantes y las estudiantes.

Lo que nos mostró Eduardo por medio de sus relatos es que su noción de alteridad pasa también por la aparición de la lugaridad. Este profesor nos permitió ver que la relación entre el exterior e interior de la escuela pasa por una situación discursiva. Es por medio del lenguaje que él logra establecer ese vínculo con los jóvenes. Acá surge una coordenada que se da entre los vectores del lenguaje y la alteridad. La coordenada, como tal, viene a ser la lugaridad. Es decir, se mantiene la idea de que el diálogo es vital en una relación pedagógica de 
alteridad, pero que, al vincularse con el espacio de los estudiantes y las estudiantes, se estaría haciendo visible su lugaridad de la ciudad.

La ciudad se hace presente porque Eduardo la tiene presente en su relación educativa. Esta se hace presente en sus clases, ya que en su espacio del aula le permite la experiencia de los estudiantes como tal. Esa ciudad que escapa a la experiencia de la escuela pareciera que se visibiliza por medio de la puesta de la alteridad en la relación educativa que propone este profesor.

A continuación, y en lo que sigue, se presentan las relaciones vectoriales que arrojaron las interpretaciones de las narraciones, Estas se presentan de acuerdo con la narrativa de cada vivencia. Estas figuras muestran los vínculos o rupturas entre el espacio de la ciudad y el interior de la institución escolar. La información corresponde a la ciudad de Bogotá, Colombia, en relación al colegio Distrital que ha sido materia de análisis en esta investigación. Los datos corresponden a los años 2015-2016.

Figura 1

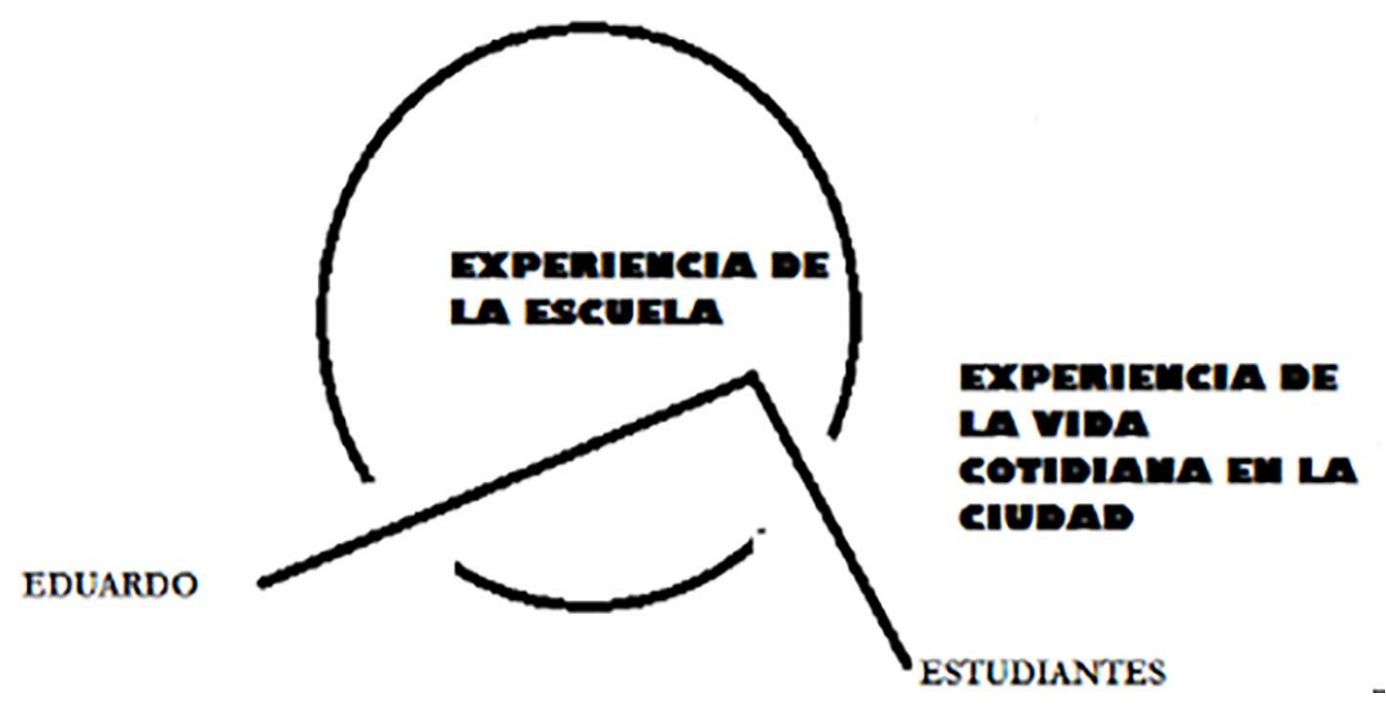

Fuente: elaboración propia con base en la interpretación de la entrevista a Eduardo

La figura 1 ilustra que la lugaridad es la que espacializa las relaciones de alteridad; también que es el espacio vital del lugar donde vienen a presentarse las relaciones de alteridad que la escuela necesita. No obstante, no se puede dejar fuera de la interpretación el 
hecho de que la experiencia de Eduardo al exterior de la escuela también incide en su forma de contemplar la relación pedagógica con los estudiantes y las estudiantes. Así pues, los vectores parten de la experiencia de la vida cotidiana en la ciudad desde la situación cultural de Eduardo y el grupo estudiantil. Esto supone un encuentro cultural en la escuela que, según el relato de vida de Eduardo, permite el reconocimiento entre sujetos a la luz de la alteridad.

\subsection{José: Coordenadas de diferenciación espacial}

José es reconocido por docentes y estudiantes como la principal figura de autoridad dentro del Colegio Distrital. En algún momento él sostiene que en la actualidad se ha perdido el respeto por la figura del docente, así que, como forma de acercarnos al problema de investigación, se le pregunta por las razones de tal afirmación. Él responde lo siguiente:

Yo pienso que puede haber varios elementos. Uno, la falta de educación de los maestros, la falta de entrega, la falta de pronto de acercarse al estudiante, eso me parece una cuestión fundamental. Los maestros nos hemos vuelto demasiado


problemas que tiene el estudiante, y del_porqué de su comportamiento, el porqué en algún momento esta triste, está hiperactivo, está rebelde, está agresivo. Entonces como que nos falta acercarnos más. (José)

En el marcaje que hacemos del párrafo se encuentra que José extraña ese acercamiento, y lo relaciona con un docente que se dedica a dictar una clase. Si nos detenemos un instante, se podría decir que el docente que se dedica a dictar una clase sencillamente se remite a estar frente a sus estudiantes mostrándoles lo que ellos y ellas deben aprender, al pie de la letra, y trabajando solamente en sus cuadernos. Por otra parte, en el último marcaje del párrafo se advierte un indicio de alteridad porque se hace referencia a la razón de la actitud de un estudiante. Es decir, no se parte del hecho de que es un estudiante problema, sino que se trata de conocer el porqué de su actuar. No se puede tener en cuenta al otro cuando se tematiza bajo una idea preconcebida. En la acción educativa, la alteridad se pone presente cuando nos preguntamos por el otro, no cuando se asumen cuestiones que predisponen frente a su actuar. Entonces, el respeto parte del conocimiento de las actitudes propias de los estudiantes y las estudiantes, más no de las ideas preconcebidas acerca de ellos y ellas. 
José trae a colación una experiencia de una estudiante que se enfrentó a otra por un problema en el barrio en el que ellas vivían. Este inconveniente se trasladó al colegio a tal punto de generarse dos bandos que se iban a ir al plano de la violencia. La situación se arregló logrando conciliar las diferencias entre las estudiantes con la ayuda de la familia. Frente a esto, José hace el vínculo entre el exterior e interior en la relación de los problemas de convivencia. Otro inconveniente grave lo describe José de la siguiente manera:

No sé si tú estabas en el colegio cuando se presentó la situación de una vez que me sacaron unos bastones, y fueron ahí y se enfrentaron con unos malandros que estaban azotando a la comunidad, entonces la situación de robo continuo, la situación de la pandilla que estaba azotando a la comunidad estudiantil llegó al colegio, y los estudiantes quisieron tomarse la justicia por las manos. Encontraron en el colegio unos bastones, y fueron y se confrontaron. Eso de una u otra forma me estaba afectando a mí porque pensaron que yo los estaba armando. Para mí fue la situación más compleja que he vivido en el colegio, entonces lo que se vive afuera si tiene incidencia adentro porque ejes conectores, porque hay campaneros ${ }^{11}$ porque hay personas que tiene celular e informan que el jíbaro ${ }^{12}$ está en tal parte. En definitiva, sí, los agentes externos afectan la convivencia en el interior del colegio (José).

Esto indica que José tiene una comprensión del exterior del colegio. Efectivamente, hay un movimiento desde el exterior al interior que no se puede obviar. Encontramos acá entonces que la relación entre el exterior e interior de la escuela no solo pasa porque el grupo estudiantil tenga experiencias que desarrollan el proceso de configuración de su individualidad, sino que atraviesa situaciones que competen, no solo a una institución educativa, sino también a todas las instituciones sociales que están en relación con la formación de los estudiantes y las estudiantes, llámense familia, Estado o colegio. Sin embargo, esto no excluye que los docentes eludan la necesidad de conocer qué ocurre en el entorno de la experiencia de ellos y ellas fuera del colegio, sea para establecer relaciones de alteridad o para hacer frente a situaciones extremas como las que comentó este docente.

Pudimos evidenciar que José es un conocedor a profundidad de las situaciones que circundan la escuela. Problemáticas de violencia, inseguridad y pandillismo se hicieron

\footnotetext{
11 Personas que avisan a los delincuentes cuando el cuerpo policial se acerca.

12 Persona que distribuye drogas.
} 
visibles por medio de la voz de este docente. Estos conflictos, para él, necesariamente deben ser excluidos de la escuela. En parte se puede compartir esta idea. Se puede sustentar que se debe excluir el conflicto, pues no se puede tolerar la violencia dentro de la institución. No obstante, lo que no se puede sacar del foco de experiencia de la escuela es la conflictividad. Esto invitaría a la escuela a traer esas experiencias, que no necesariamente son las de los docentes, para desde ahí poder desarrollar procesos de alteridad entre el grupo de estudiantes.

Si se invisibiliza la conflictividad no se podría hablar de una situación espacial en educación porque sencillamente no habría espacio. Para que haya coordenadas, es necesario el espacio. Si queremos coordenadas entre el vínculo de la experiencia de la ciudad y de la escuela para buscar la lugaridad por medio de la alteridad, sencillamente sería una empresa que no se puede llevar a cabo.

La situación espacial de la experiencia de José nos dejó ver que la situación vectorial partió del origen de la escuela, pero no permitió establecer claramente la coordenada con la relación de la ciudad. Esto en una función matemática no es posible puesto que siempre que hay un vector, necesariamente hay una coordenada. Lo que sucede desde la experiencia de José, a la luz de un análisis espacial, es que, a pesar de su conocimiento de las experiencias de los estudiantes y las estudiantes alrededor del colegio, el punto de encuentro cultural siempre se ancló al interior del colegio. El vector no salió de ahí, por lo tanto, la experiencia de la relación educativa dentro de la escuela se ceñiría solo a ese espacio. Esto podría ser representado como se muestra en la figura 2 : 
Figura 2

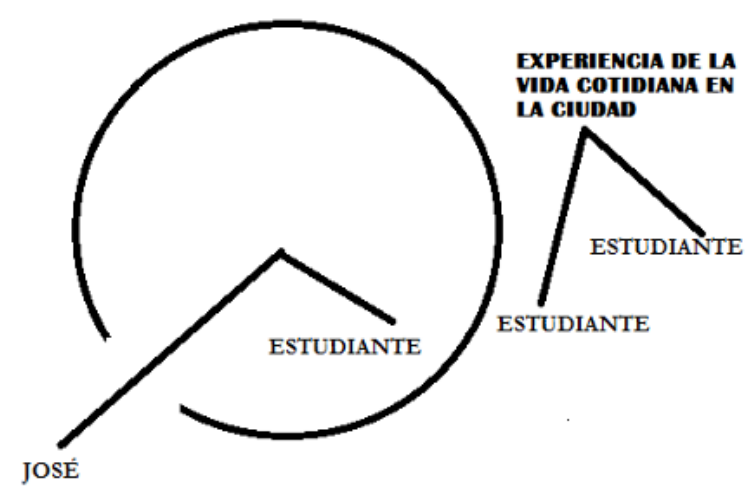

Fuente: Elaboración propia con base en la interpretación de la entrevista a José

Hay que insistir en que lo que se puede comprender de la experiencia de José, es la búsqueda constante por el bienestar de sus estudiantes. Estas acciones están enmarcadas en sus preceptos de disciplina y respeto. Conoce el espacio circundante del colegio y las problemáticas del barrio como lugar de experiencia de ellos y ellas. Esto ha permitido un manejo de conflictos radicales como el pandillismo o inseguridad. Aunque la teleología de estas acciones supone un compromiso con la formación ética del grupo de jóvenes, la situación espacial aparta la experiencia del espacio exterior de la escuela. Por lo tanto, se excluye la experiencia de espacio que tienen. Sus lugares se convierten en no-lugares que dificultan una relación de alteridad con el grupo de jóvenes, pues esto supone un desconocimiento de su lugaridad y todo el cúmulo cultural que esto trae consigo.

\subsection{Víctor: Heterotopía y no-lugar, ciudad como lenguaje}

Víctor es un joven amante de la música rap y el grafiti.

El grafiti es coger un marcador, o una lata de aerosol y rayar una pared. El grafiti se vive, desde el momento en que uno se despierta hasta que se acuesta. Hay muchas personas que piensan que por el hecho de que raye una pared somos vándalos, que no hacemos nada. Sí, que somos vagos o gamines o algo así. Pero no es así, el grafiti es una forma de expresión (Víctor). 
El grafiti, más allá de ser una forma de expresión gráfica, pasa a ser una parte de la identidad de Víctor. No es solo el hecho de rayar una pared, eso lo puede hacer un niño de poca edad que no le haya un sentido a lo que hace. Rayar implica plena conciencia de lo que se hace y del significado particular que tiene para los raperos. Por esto último es que Víctor se siente mal cuando la sociedad los considera como personas que cometen un mal al rayar algo que está a la vista de todo el mundo.

Esa opinión, que Víctor considera que se tiene de los jóvenes que hacen grafiti, constituye parte de un imaginario de las personas que habitan la ciudad. No es raro escuchar a alguien referirse en palabras despectivas cuando ven las paredes rayadas con grafitis. Se buscó ligar esa opinión que se da en la sociedad en general con las que se expresan dentro del colegio, a propósito de esta forma de expresión. Al respecto nos dijo:

Mire, mi hermana es grafitera, mis amigos son grafiteros. Entonces uno como que lo encasillan y le dicen a uno, no, que los vándalos, y que son unos ineptos que no saben nada. $Y$ pues como que yo me pongo a pensar que pues por qué dicen eso. Cada persona tiene una forma de expresarse. $Y$ pues a nosotros nos gusta expresarnos por medio de la pintura, del arte (Víctor).

Lo que se encuentra en el descontento de Víctor es que ese desconocimiento que hay en la ciudad con respecto a su expresión, que él considera arte, hace de ellos y ellas un estereotipo negativo que parte del desconocimiento de la intencionalidad de sus acciones. Víctor siente que esa forma negativa en la cual son vistos pasa al colegio por medio del puente, llamado profesores, que permite continuar con esa interpretación errónea de sus acciones. Cuando Víctor dice que cada uno tiene una forma de expresarse recurre a su propia realidad, que desde su perspectiva es totalmente normal, pues responde a la necesidad de expresar su individualidad como lo hace cualquier otra persona. En el caso particular del colegio, para Víctor, los profesores mantienen este tipo de ideas erróneas. Esto supone una escisión entre la experiencia de la ciudad de Víctor y la escuela.

La ciudad se plasma en la experiencia de Víctor. El habitar heideggeriano casi que se hace presente a causa de la forma como él concibe el arte. Él no ve la pared de una ciudad como la vemos todos, sino como algo a lo que se le puede dar vida por medio de su lata. Entonces, este espacio es el lugar de experiencia en el cual Víctor puede hallarle significado a su forma de expresión. Para esto es necesario el recorrido de la ciudad, ahí, donde el colegio 
no está presente. Eso que la escuela puede desconocer, por lo menos desde lo que relató Víctor, se visibiliza en las paredes de sus recorridos urbanos.

Por los lados de la avenida Boyacá, por la 68, había un concesionario vacío hace ya mucho tiempo. Habíamos unas pocas "firmas", y pues unos aerosoles, y que vamos a pintar, entonces hicimos unos tags ${ }^{13}$, y comenzaron a tacharlos, a escribirles cosas encima. Pasó el tiempo, yo me monté en aerosoles, y les dije, "muchachos, vamos a pintar", nos fuimos todos, nos fuimos como cinco y otros. Claro, íbamos los que pintábamos, y los de respaldo. $Y$ pues nada, eso era como un vidrio grandísimo, y nosotros ahí dándole. Nos chiflaban, nos echaban la madre ${ }^{14}$, "eh que cójanlos" "eh que no sea sapo ${ }^{15 "}$ les decíamos. Pues claro, la adrenalina, la gente gritando (Víctor).

Estos lugares que son olvidados, intrascendentes $u$ omitidos por la experiencia cotidiana, cobran relevancia para la experiencia de Víctor y sus amigos. Mientras para los demás es algo vacío y sin importancia, para ellos y ellas se convierte en el lugar que le da significado a su identidad porque es ahí donde pueden ejercer su medio de expresión, incomprendido por muchos. Ese lugar deshabitado y sin ningún valor pasa a cobrar relevancia, para bien o para mal, en el momento que empiezan a pintarlo.

No es una ciudad inerte, es una ciudad viva. $Y$ vive precisamente porque es la lugaridad de Víctor. Es ahí donde él aprende y entiende sus procesos de identidad. No fue la escuela precisamente la que lo llevó a tener esa percepción de la ciudad. Es el habitus del espacio de la ciudad lo que construye su identidad.

Esa pared ignorada por nosotros se convierte en un no-lugar. Sencillamente porque no reflexionamos desde ella. Así lo ve Víctor, pues siente que hay un desconocimiento en esta institución educativa acerca de lo que se vive en la ciudad. En este sentido, esta ignorancia por parte de algunos sectores de la escuela no permite que se pase del no-lugar al lugar. Por lo tanto, la ruptura que crea el límite entre el espacio de la ciudad y la escuela se hace presente.

\footnotetext{
${ }^{13}$ Representación gráfica que diferencia a un grafitero de otro.

${ }^{14}$ Significa que los estaban insultando.

15 "No sea chismoso".
} 
La heterotopía foucaultiana se evidencia en la medida en que Víctor es uno en el colegio, pero es otro fuera. Esto no tendría nada de malo, pues todos manejamos roles según el sitio en el que estemos, si no fuera porque Víctor tiene que cubrir su forma de vida en la ciudad por el miedo de ser estigmatizado. No obstante, el relato de este estudiante permite ver que sí ha sentido el reconocimiento en el colegio por su arte. Sin embargo, estos momentos episódicos se ven opacados por el afán de algún sector de la escuela para que se repriman estas formas de ver el mundo desde la ciudad.

La experiencia de Víctor impide que se pueda interpretar como una cinta de möbius, puesto que se diferencian los espacios de la escuela y la ciudad a la manera de un límite. Estos se repelen y no hallan su vínculo. Veamos a continuación la figura que representa esta situación espacial:

Figura 3

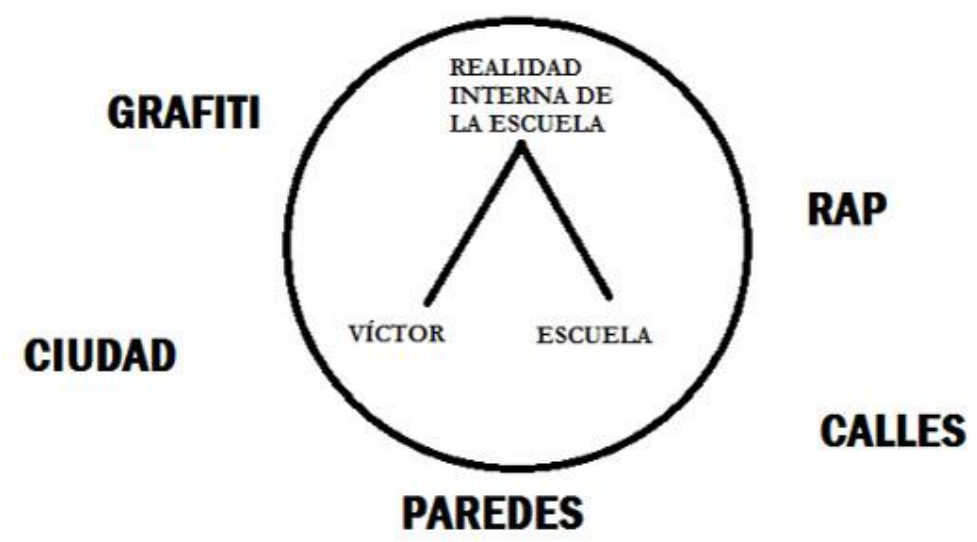

Fuente: elaboración propia con base en la interpretación de la entrevista a Víctor

Acá las coordenadas se ven desde el centro de la escuela como origen del vector de experiencia de Víctor, no por decisión propia, sino por las mismas mecánicas culturales de este espacio. Así pues, hablar de interculturalidad y alteridad se torna difícil en la medida en que la lugaridad de Víctor, su lugaridad de la calle, de la pared y del grafiti pasan a ser espacios sin importancia en el discurso educativo. 
Sumado a esto, toda la ciudad se convierte en lenguaje (García-Canclini, 1997). La ciudad le habla a Víctor, lo llama para que viva con ella, en ella. Más que un fenómeno físico, la ciudad es un espacio existencial que escapa a la racionalización de la vida del estudiante que pretende la escuela. Víctor dialoga con la ciudad. No es algo unilateral de la experiencia del estudiante, sino que es la ciudad la que devuelve la mirada y responde al actuar de Víctor.

\subsection{Camila: Vectores cerrados}

Camila luce una expansión en su oreja, piercings en su boca y un color de cabello azul. Este tipo de estética, comenta, hace parte de la expresión de la música hardcore. El acercamiento que hicimos a su experiencia se movió, en principio, en el plano de la indagación fuera del colegio, en la sociedad urbana en la que ella se desenvuelve y expresa libremente su estética y gustos. Se notó en ella un fuerte sentido crítico frente a situaciones ideológicas actuales, tal y como se ve a continuación:

Pues es que la ciudad prefiere ver a una mujer con siliconas en los senos, en la cola, que ver a una mujer tatuada y verla perforada. Aunque las dos son modificaciones, una modificación va como a ser algo más del montón, y pues lo que yo hago es no modificarme de una manera distinta y no caer en los clichés de la sociedad (Camila).

En sus palabras se halla una postura crítica frente a la sociedad de consumo. Su forma de ver al género femenino, en sus palabras, difiere del "montón". Como ella expresa, ambas son modificaciones corporales, pero es indudable que las de Camila no hacen parte de lo que la sociedad de consumo entendería como femenino. Sumado a esto, se acentúa más la idea que su estética es una confirmación de su identidad. Se nota acá una escisión entre la experiencia del colegio y la del exterior de la ciudad. Por esto se puede decir que había dos Camilas: la del colegio, que cubría sus gustos y estética particular, y la del exterior del colegio.

El gusto por el hardcore la lleva a frecuentar bares donde se escucha ese género musical. Ella sostiene que acude ahí por lo siguiente: "Pues es que yo ahí encuentro personas que no encuentro en el colegio, personas que comparten mis gustos, esto es muy bueno. Uno puede conocer gente nueva, y conversar a gusto porque nos íbamos a desenvolver del mismo modo" (Camila). El agrado que Camila siente con su experiencia exterior pasa por lo que no va a encontrar en el colegio. Allá, fuera del colegio, hay personas afines a ella, conocidas o por conocer. Pero la situación de Camila en ese lugar también se relaciona con la cuestión 
del diálogo. La necesidad de la palabra pasa por encontrar la posibilidad de intercambiar ideas sobre un tema en común, cuestión que no halló en el colegio.

Entre esa experiencia de lugar de Camila se encuentra su relato sobre los conciertos de hardcore. Para ella la sensación que le despierta es, en sus palabras, "como poder liberarse, como sentir cosas chéveres como cantar, como sentir la adrenalina" (Camila). Esa vivencia de Camila es poco conocida para el entorno escolar, a excepción de sus pocas amigas. Para el colegio sería impensable imaginar a Camila en medio de un evento de esos, pues ella trata de esconder al máximo sus modificaciones corporales para que no se le llame la atención.

De por sí, este tipo de expresión que no es la habitual en un concierto de un tipo de música más masivo, suele impresionar a los que desconocen esta cultura. Frente a este tipo de manifestaciones musicales es frecuente escuchar, entre las personas que no están familiarizadas con esto, la frase: "esa es música para locos". Así mismo lo reconoció Camila cuando se le preguntó qué pensarían las personas cuando ven que en un concierto se hace un pit mosh16: "Pues dirían 'esta gente está como loca'. De hecho, hasta lo he escuchado porque hay gente muy cercana a mí que dice 'esta gente está drogada o cosas así', pero pues sé que lo dicen porque no saben" (Camila).

Para hablar de una relación directa entre su estética y el colegio, ella expresó haberse sentido discriminada por un docente, aun cuando ella trata en la institución de mantener un perfil bajo:

En el colegio había niñas con el cabello teñido incluso de azul, entonces yo tenía pintado el cabello de rojo. Entonces él por esa razón me sacó del colegio, fue como "usted no puede entrar así al colegio", esto no va con usted, esto no va con la institución". Pues entonces el hecho que el dijera eso, la verdad que sí, sí me sentí rechazada (Camila).

Varias situaciones que van en un sentido contrario a las relaciones de alteridad se encuentran en lo que comenta Camila. En primer lugar, el hecho de haber sido excluida de la institución hace una división tajante entre el exterior e interior de la escuela. Quiere decir esto que, en vez de existir una orientación, si se estuviera de acuerdo en que esto es un tipo de falta, pues el fin de esta acción no se puede llevar a cabo porque a la estudiante se excluye del espacio de la escuela. También se evidencia discriminación, ya que no se deja acceder a una institución pública en la que ella tiene el derecho a estar. Finalmente, el hecho de que

16 Ahí los asistentes se reúnen en la mitad del público a empujarse mientras suena la música 
indicara que eso no iba con ella, es una agresión en contra de algo tan personal como es el cuerpo. Si desconoce el cuerpo, entonces se desconoce a la persona. En este relato el profesor opina que esa no es la personalidad de ella, con base en lo que la persona que está en posición de dominación, en este caso el docente, le ordena qué debe ser.

Ante un hallazgo que no tiene que ver con una relación educativa en el marco de la apertura de la alteridad, nos estamos enfrentando a una situación esencial. Por lo tanto, acudiendo a esta experiencia, se puede indicar que la situación de alteridad podría ir en contravía de esta última experiencia que relata Camila, y establecer que se debe: 1 . Orientar a la estudiante desde el mismo lugar del colegio 2. Vincular la cultura de la estudiante con el colegio 3. Respetar el cuerpo del estudiantado en general.

La experiencia de Camila muestra que hay una ruptura entre su experiencia de la vida cotidiana y el colegio. La coordenada que se puede hacer entre el encuentro de vectores que parten, por un lado, de la experiencia de la cotidianidad de esta estudiante, y por el otro, del propio espacio de la escuela, se hace imposible para la experiencia de ella. Observemos la siguiente ilustración:

\section{Figura: 4}

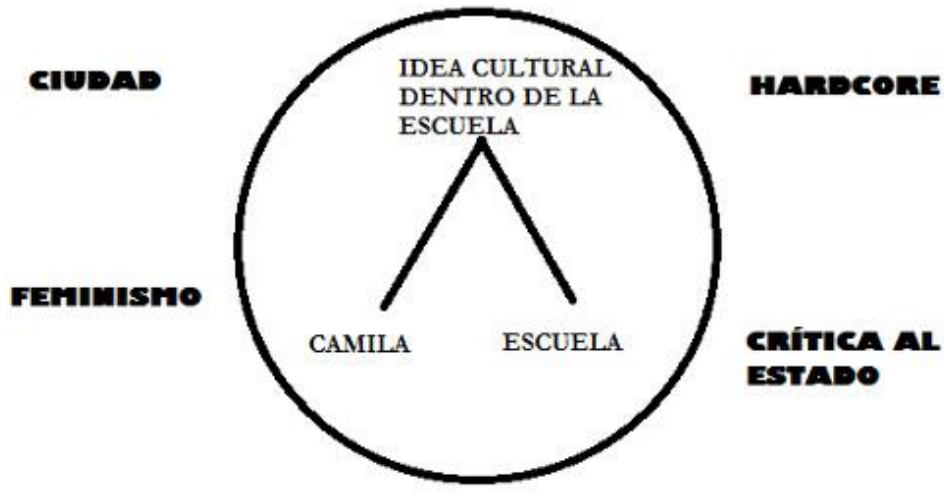

Fuente: elaboración propia con base en la interpretación de la entrevista a Camila

La coordenada de la experiencia de Camila permite ver que los vectores que representan su experiencia cultural dentro de la institución escolar surgen del propio espacio 
del colegio. La búsqueda de homogeneidad en los estudiantes y las estudiantes no permite la ubicación de una coordenada exterior, puesto que se excluyen las experiencias culturales particulares con las que viene ella.

Se pudo observar que el hecho de que su situación cultural haya sido por influencia de la familia, que haya encontrado pocas personas que comparten sus gustos, y que finalmente la escuela no tuvo nada que ver con el desarrollo de su identidad, sugiere que existe una ruptura entre espacios. En el colegio fue confrontada por su color de cabello, que reñía con una norma tácita de la institución, además ocultó sus tatuajes y, en síntesis, trató de evadir para el colegio sus gustos desarrollados en su lugar de experiencia fuera de la escuela. Esto sugiere que no se permite ver de manera clara una relación entre la lugaridad de los estudiantes y el colegio.

\subsection{Michel: La coordenada del hogar}

Michel narra que creció escuchando lo que para ella es buena música, el rock, gracias a la influencia de su familia. Ella afirma que no es una joven que sale mucho de su casa. "Mi vida es del colegio a la casa y de la casa al colegio, sí salgo a veces pues con mis amigos. De pronto no sé a cine, o van a mi casa, o yo iba a la casa de ellos, cosas así" (Michel). Por esta situación, no se puede decir que Michel vincule su experiencia cultural con lugares urbanos, en sentido estricto. Pero no solo la familia influenció a Michel:

Pues lo que te digo, como no salía mucho, yo estaba más bien en la casa y pues sí, me gustaban cosas de lo que escuchaban mis papás, pero pues me metía en internet a ver videos y esas cosas, y pues ahí vi cosas que me llamaron la atención y aprendí de ahí. Recuerdo mucho cuando vi un video de Slikpnot, esas máscaras eran muy chéveres, claro que daban miedo, pero cuando uno escucha las entrevistas de esos manes, las cosas que dicen son como, yo no sé ¿inteligentes? Entonces mientras mi hermano escuchaba su reguetón (risas) yo me metí en mi cuarto a escuchar rock (Michel).

Encontramos un plano de alejamiento de los lugares de la experiencia de la ciudad. Es en la soledad de su cuarto en la que también desarrolló sus gustos. Pero no es el cuarto en sí, sino la relación con lo que encuentra en la pantalla de su ordenador lo que deja entrever la importancia que tiene la internet en su desarrollo cultural particular. Mientras que la familia la 
influencia, es la internet la que perfila su identidad. A diferencia de otras experiencias que se pueden encontrar, la relación con otros jóvenes no desarrolla su proceso de identidad.

Con respecto a su experiencia en el colegio, Michel se refirió a la necesidad del diálogo para solucionar los conflictos que ahí se presentan. Ella mencionó a un profesor de ciencias sociales que tuvo. Lo describió como un docente calmado y suave en el trato ellos y ellas:

Pasaba un conflicto en el salón y pues él, a menos que fuera muy grave, él siempre, primero hablaba, y si lograba conciliar algo con el estudiante, entonces, pues bien, entonces de lo contrario pues ya se iba a lo mayor, que era coordinación o rectoría (Michel).

Michel explicó que, desde su experiencia, las actitudes represivas de algunos profesores a fin de cuentas no sirven. Fue evidente en la conversación que siempre se sintió más cómoda con los llamados de atención en los que primaba el diálogo:

Yo creo que, si funciona más el llegar a un consenso con la otra persona, no hay mejor método que hablar con alguien ¿sí? Como, venga, pero por qué pasan esas cosas, y por qué usted se porta de determinada manera. ¿Sí? Como ¿de verdad quiere llamar la atención, o esa es su forma de ser realmente? Porque pues yo no puedo negar que si hay gente que lo hace solamente para llamar la atención. Pero hay gente que simplemente esa es su manera de ser y ya. Son libres de expresarse y yo creo que quitándoles o poniéndoles reglas pues no es la manera (Michel).

Se encuentra en las palabras de Michel que el diálogo permite que haya una interacción entre dos. Pareciera que a lo que se refiere ella es, más que a un castigo, a un acuerdo entre dos personas acerca de un conflicto. Más que castigar, cuando Michel nos dice que hay personas que realizan acciones para llamar la atención o porque esa es su personalidad, es como si ella estuviera haciendo una invitación a que es por medio del diálogo que los docentes en verdad podemos conocer a los estudiantes y las estudiantes, y, a partir de ese conocimiento, poder solucionar un conflicto.

Con respecto a la indagación que hicimos en la experiencia de Michel con respecto al espacio urbano, hay que aceptar que estuvo difuso en sus relatos. Esto tuvo que ver con la experiencia cotidiana particular de Michel, a saber: el afecto por el lugar de su casa. Esta 
experiencia de lugar se puede decir que es topofílica — siguiendo a Tuan (2007) —, debido al vínculo que ella tiene hacia su hogar y modelo de familia.

Aquí emerge un concepto que nos invita a pensar el espacio virtual, pues es ahí, según vimos en el relato, donde ella aprende, se apropia e identifica con los discursos que de una u otra forma se dan en su experiencia con la música. También encontramos la lugaridad de un espacio virtual, pues ella afirma que por medio de la Red pudo conocer la música de su gusto. Aquí no hay relación presencial con el otro. Pero no por esto, no se puede decir que no haya relación con el otro. Esta situación espacial se puede representar de la siguiente manera:

\section{Figura 5}

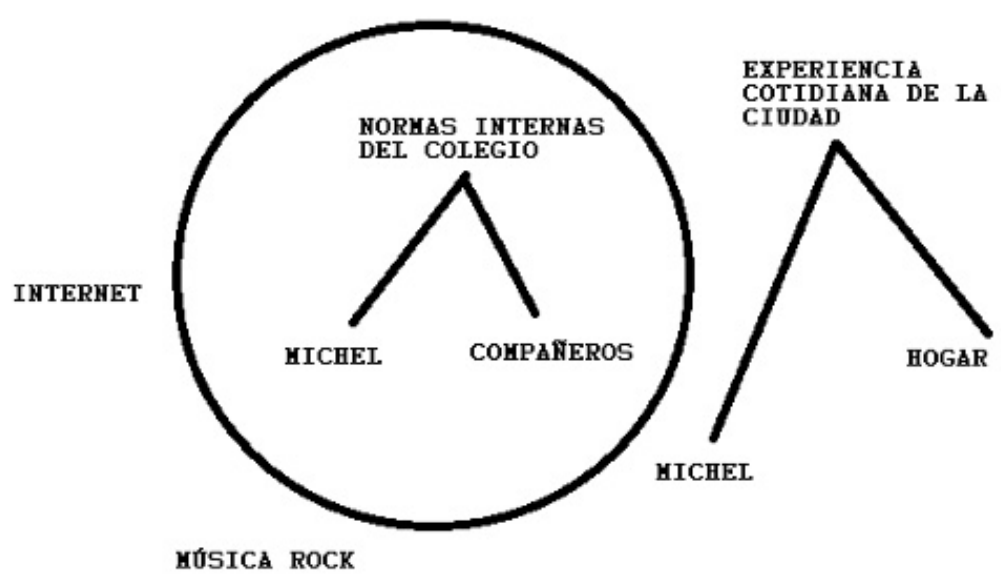

Fuente: elaboración propia con base en la interpretación de la entrevista a Michel

No se puede interpretar que esta situación de Michel no sea una experiencia de la ciudad. Retomemos lo que vimos con la idea que nos propone Hiernaux (2006) con respecto al concepto ciudad fugaz. Esta supone que trajinamos todo al instante, no la vivimos, sino que pasamos de todo, convirtiendo la ciudad en sí misma en un no-lugar. Esta pareciera ser la experiencia de ciudad de Michel que la remite al espacio familiar. 
La ausencia de experiencia con la ciudad tampoco implica que no haya una lugaridad o relación con el espacio. Lo que encontramos es que siguen las mismas significaciones que se encuentran en una experiencia de ciudad, pero desarrolladas en otros lugares. Esto responde a que Michel vive en la ciudad, tiene experiencia de ella. Así como ella dice que va del colegio a la casa y de la casa al colegio, también tiene que pasar por una calle de la ciudad, experiencia distinta a una vereda, quebrada o paisaje rural, -espacios paradigmáticos del entorno rural一. Ahí ya existe una experiencia de ciudad. Ella se relaciona con citadinos, razón por la cual ahí también está la experiencia urbana. Además, estudia en un colegio urbano y se relaciona con la experiencia de la ciudad que tienen sus profesores y compañeros estudiantes.

\section{Consideraciones finales}

Encontramos dos situaciones emergentes en los relatos de los involucrados en esta investigación, a saber: la relación entre el interior y exterior de la institución escolar. En torno a este vínculo (o ruptura) hemos optado por destacar conceptos, vivencias y contendidos simbólicos del referente social de los relatos de vida que más fuerza cobraron durante la interpretación de las narrativas. Presentamos estos hallazgos por medio de la siguiente situación espacial:

\section{Figura: 6}

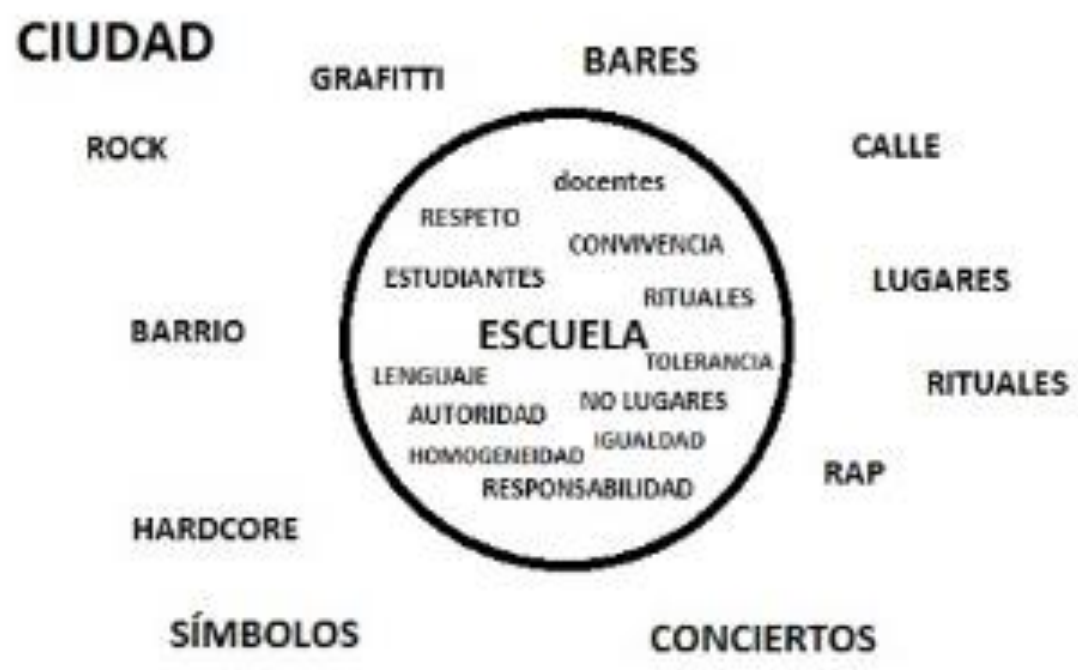

Fuente: elaboración propia con base en la totalidad de la interpretación de las entrevistas 
En el caso concreto de la figura anterior encontramos, desde el interior, a la escuela urbana como una utopía, un espacio en donde se dan, o se pretende, se establezcan parámetros de idealidad en las relaciones sociales que ahí se presentan. Los estudiantes y las estudiantes deben llegar al total respeto y tolerancia por el otro. Pero a juzgar por lo que se halló en los relatos de vida, esta idealidad se ve siempre interrumpida por contingencias que exceden, incluso, la labor educativa de quienes orientan los procesos pedagógicos al interior de este espacio. Casos de pandillismo, drogadicción, embarazos a temprana edad y de violencia intrafamiliar responden a situaciones externas que, si bien no competen en su totalidad a la escuela, no pueden ser eludidas de la experiencia de esta.

Por lo anterior, la situación espacial muestra experiencias directas vistas desde conceptos, eventos, acontecimientos e ideologías que hacen parte de la ciudad. Estas situaciones pareciera que pierden su fuerza cuando se cierran las puertas de la escuela. Por consiguiente, se ve una escuela aislada, pero que paradójicamente quiere que sus estudiantes se vinculen a la sociedad en su etapa como ciudadanos para que ejerzan una serie de derechos y deberes.

Los lugares existen fuera de la escuela, pero se convierten en no-lugares en su interior, de ahí su ubicación exclusiva en la anterior representación espacial. Toda la carga semántica de la ciudad se invisibiliza, bien sea por una situación de control frente a las situaciones negativas que se dan allá —como lo pudimos ver en los esfuerzos que realiza el docente José-, o en situaciones de desconocimiento, tal y como lo hace evidente Víctor en la relación de estos discursos con su experiencia en la escuela.

Según los conceptos de la gráfica, estos viven en el interior de la escuela en su búsqueda de formar en esos términos a los estudiantes y las estudiantes. No obstante, ese habitar deja de ser significativo en la medida que está contenido en la institución educativa. Esto conlleva una ruptura con el mundo real en donde se desenvuelven esos conceptos que busca desarrollar la escuela con ellos y ellas.

Llama la atención de la representación espacial que traemos a colación, que en el exterior no ubicamos sujetos. Pareciera entonces que los eventos se movilizan por sí mismos sin necesidad de un componente social o de la acción del individuo. Sabemos que no funciona de esta manera. Los discursos son movilizados por el sujeto, bien sea desde una perspectiva constructivista, en el sentido social amplio del término, o en la relación individuo-individuo propia de los análisis de la interacción simbólica. En este sentido, si es nuestro núcleo de 
análisis el espacio de la escuela, entonces son los actores de esta institución escolar los que movilizan desde el exterior los conceptos que salieron a flote en esta investigación.

Los estudiantes exigen ser reconocidos desde su lugaridad. Para que esto se dé son necesarias las relaciones de alteridad. La lugaridad está presente siempre en nuestra realidad cotidiana, es una condición del ser humano, pero es la alteridad la que nos permite acceder al lugar del otro que no podemos conocer por medio de nuestra experiencia como docentes.

Si nos fijamos en el esquema anterior, ni lugaridad ni alteridad se hacen presentes. Esto, porque mientras haya un límite espacial, también hay un límite para estos conceptos. Esta división espacial entre el exterior e interior de la escuela genera un manejo del lenguaje que excluye e imposibilita las relaciones de alteridad. En la escuela, la lugaridad sin alteridad no existe puesto que no se dejaría entrar al otro a la experiencia de ese espacio. No se puede interpretar a los estudiantes y las estudiantes en tanto otros, solo desde su facticidad en la escuela. Esto sería caer en el problema hermenéutico de interpretar un texto solamente desde la época en que se creó, y por ende, dejar de lado el horizonte de comprensión que vincula al texto con el lector y su experiencia actual (Gadamer, 2003). Ahora bien, optemos por abrir los límites y convertirlos en fronteras entre la escuela y la ciudad, y observemos la situación espacial que, en consecuencia, se genera en la siguiente figura:

Figura 7

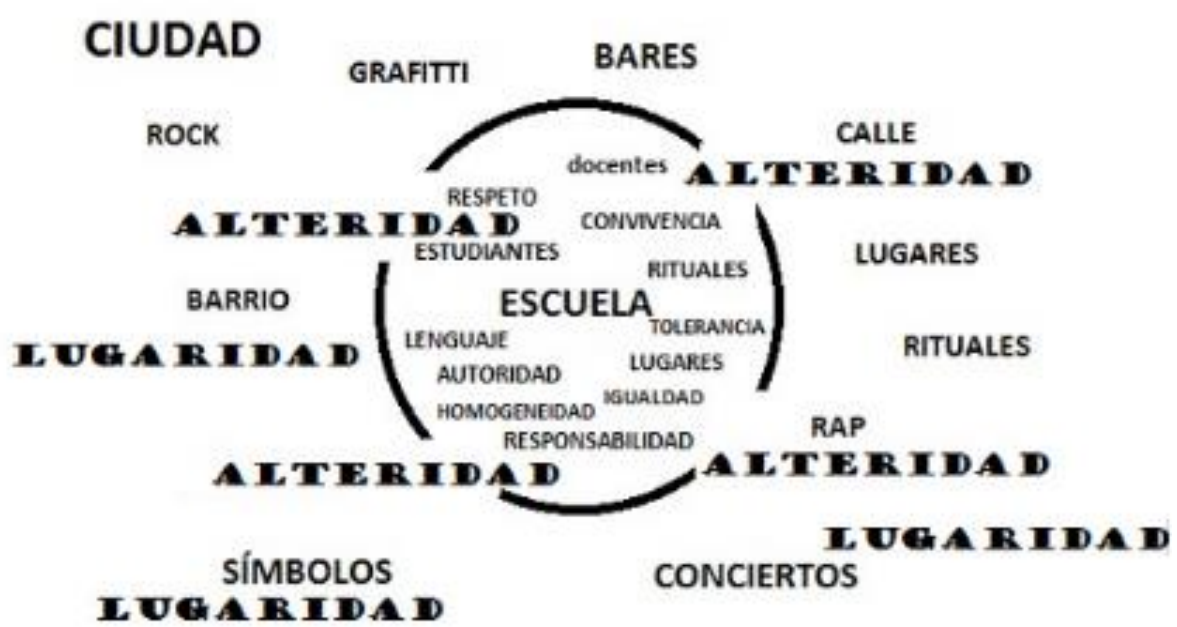

Fuente: elaboración propia con base en la interpretación de la totalidad de las entrevistas 
Para que se abran paso los discursos dentro de la escuela desde el exterior, según se pudo confrontar entre la teoría y la interpretación de los relatos de vida, se necesita por parte de la escuela algo más que saber que existen y están en algún lado de la ciudad. La acción educativa, que hemos nombrado como pedagogía hermenéutica del lugar, abre paso a la idea de que se puede comprender e interpretar el actuar de los estudiantes y las estudiantes así desconozcamos su realidad significativa. Es el lenguaje el que permite esto. En la ilustración el no-lugar pasa a ser lugar. La consecuencia de esta situación pedagógica la ilustramos por medio de la siguiente figura:

\section{Figura 8}

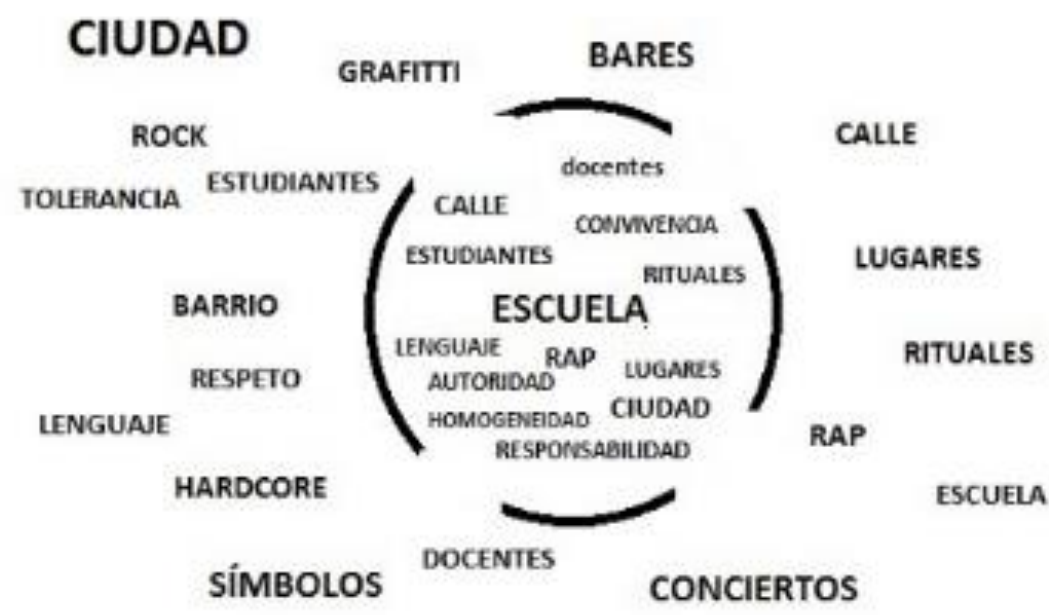

Fuente: elaboración propia con base en interpretación de la totalidad de las entrevistas

¿La situación espacial de la figura anterior da a entender que la lugaridad y la alteridad no se encuentran presentes? Sí lo están. Están presentes porque son los conceptos los que ya han entrado a la escuela y, asimismo, han podido acceder al espacio de la ciudad desde su interior. Es el espacio de la lugaridad y la alteridad. Ya no existe una utopía, solo heterotopías que coexisten entre los espacios adyacentes que se encuentran presentes en la relación social. De ninguna manera se puede pensar como una teoría de los sistemas a la manera de Luhmann $(1984,1996)$, porque para que los conceptos, vivencias y situaciones cotidianas se hagan presentes en el espacio, tal y como se hizo presente en esta investigación, es necesaria la interacción entre individuo-individuo. 
Las instituciones también se relacionan entre sí, pero no a la manera de una red estructuralista. Son las vivencias del sujeto las que permiten esto. Instituciones por sí mismas no existen porque estas son permeables a la experiencia del sujeto. Alteridad y lugaridad están difuminadas en el espacio, no es necesario destacarles ya que ellas son los conceptos espaciales, y también son el espacio discursivo que moviliza todo.

La figura 5 acentúa a la escuela como un límite que excluye la situación cultural de los estudiantes y las estudiantes. En este panorama se dificulta la idea de establecer relaciones de alteridad y lugaridad con ellos y ellas. Además, esta ilustración concuerda con los límites de la escuela que, además de ser físicos, son discursivos. La figura 6 evidencia también esos momentos en que los estudiantes fueron, o quisieron ser reconocidos desde su experiencia cultural.

Por todo lo anterior, se puede sostener que el docente no puede ser un conocedor a profundidad de todas las experiencias culturales de los estudiantes y las estudiantes. Dada la multiplicidad, complejidad y heterogeneidad de estas, es una labor que pareciera salirse de las manos. Empero, proponer las condiciones que permitan trabajar con esas situaciones culturales para que ellos y ellas puedan expresar esa experiencia de mundo, es una situación distinta. Son los procesos de alteridad los que permiten llevar a cabo esto.

Una pedagogía hermenéutica del lugar permite identificar las situaciones donde se dan esas experiencias culturales. Esto, porque cuando se está al tanto de la lugaridad de los estudiantes y las estudiantes, se atiende al reconocimiento de su experiencia espacial de mundo, de su espacio vivido o de su mundo de la vida cotidiano. Entender que los estudiantes y las estudiantes son culturalmente activos y que no necesariamente siguen el lineamiento cultural que para ellos y ellas tiene la escuela, significa un paso necesario para reconocerlos desde su diferencia. Somos iguales porque somos seres humanos, pero somos diferentes porque somos sujetos con experiencias culturales distintas.

\section{Referencias}

Augé, Marc. (2000). Los no lugares. Espacios de anonimato. Una antropología de la sobremodernidad. Barcelona: Editorial Gedisa S.A.

Augé, Marc. (2004). ¿Por qué vivimos? Por una antropología del espacio. Barcelona: Editorial Gedisa S.A. 
Bachelard, Gaston. (2005). La poética del espacio. Buenos Aires: Fondo de cultura económica.

Bárcena, Fernando, y Mèlich, Joan Carles. (2000). La educación como acontecimiento ético. Natalidad, narración y hospitalidad. Barcelona: Paidos.

Bolívar, Antonio. (2002a). El estudio de caso como informe biográfico-narrativo. Revista Arbor, 171(675), 559-578. DOI: http://dx.doi.org/10.3989/arbor.2002.i675.1046

Bolívar, Antonio. (2002b). “¿De nobis ipsis silemus?”: Epistemología de la investigación biográfico-narrativa en educación. Revista Electrónica de Investigación Educativa, 4(1), 40-65. Recuperado de http://redie.uabc.mx/redie/article/viewFile/49/91

Bolívar, Antonio y Domingo, Jesús. (2006). La investigación Biográfica-Narrativa en Iberoamérica: Campos de desarrollo y estado actual. Forum: Qualitative Social Research, 7(4). Recuperado de http://www.qualitativeresearch.net/index.php/fqs/article/view/161/357

Bolívar, Antonio, Domingo, Jesús y Fernández, Manuel. (2001). La investigación biográficonarrativa en educación. Enfoque y metodología. Madrid: Muralla.

Bolívar, Antonio y Porta, Luis. (2010). La investigación biográfico narrativa en educación: entrevista a Antonio Bolívar. Revista de Educación, 1(1), 199-210. Recuperado de http://fh.mdp.edu.ar/revistas/index.php/r educ/article/view/14/58

Bourdieau, Pierre. (2007). El sentido práctico. Buenos Aires: Siglo XXI editores.

Connelly, Michael y Clandinin, Jean. (1986). On Narrative Method, Biography and Narrative Unities in the Study of Teaching. Recuperado de http://files.eric.ed.gov/fulltext/ED277664.pdf

Foucault, Michel. (1999). Estética, ética y hermenéutica (Obras esenciales, Vol. 3). Barcelona: Paidos.

Gadamer, Hans George. (1992). Verdad y Método II. Salamanca: Editorial sígueme.

Gadamer, Hans George. (2003). Verdad y Método I. Salamanca: Editorial sígueme.

García-Canclini, Nestor. (1997). Imaginamos urbanos. Buenos Aires: Editorial universitaria de Buenos Aires.

Giroux, Henry. (1997). Cruzando límites. Trabajadores culturales y políticas educativas. Barcelona: Paidos

Heidegger, Martin. (2010). El arte y el espacio. Barcelona: Editorial Herder. 
Hiernaux, Daniel. (2006). Repensar la ciudad: la dimensión ontológica de lo urbano. Revista Liminar. Estudios Sociales y Humanísticos, 6(2), 7-17. Recuperado de: http://www.redalyc.org/pdf/745/74540202.pdf

Larrosa, Jorge y Skliar, Carlos. (2009). Experiencia y alteridad en educación. Rosario: Ediciones Hommo Sapiens.

Lefebvre, Henry. (2013). La producción del espacio. Madrid: Ediciones Capitan Swing.

Levinas, Emmanuel. (1993). Entre nosotros. Ensayos para pensar el otro. Madrid: Editorial pre-textos.

Levinas, Emmanuel. (2000). Ética e infinito. Madrid: A. Machado libros.

Levinas, Emmanuel. (2001). La huella del otro. México D.F.: Editorial Taurus.

Levinas, Emmanuel. (2002). Totalidad e Infinito. Ensayo sobre la exterioridad. Salamanca: Ediciones Sígueme.

Levinas, Emmanuel. (2003). De otro modo de ser o más allá de la esencia. Salamanca: Ediciones sígueme.

Luhmann, Nicholas. (1984). Sistemas Sociales. Barcelona: Anthropos-UIA-CEJA.

Luhmann, Nicholas. (1996). Teoría de la sociedad y pedagogía. Barcelona: Paidós.

Magendzo, Antonio. (2006). El Ser del Otro: un sustento ético-político para la educación. Revista Polis, Revista de la Universidad Bolivariana, 5(15). Recuperado de http://www.redalyc.org/articulo.oa?id=30517306007

Martínez, Ion. (2013). Henri Lefebvre y los espacios de lo posible. En Henri Lefebvre, La producción del espacio (pp. 9-28). Madrid: Ediciones Capitan Swing.

Massey, Doreen. (2005). La filosofía y la política de la espacialidad, algunas consideraciones. En Leonor Arfuch (Coord.), Pensar este tiempo Espacios, afectos, pertenencias (pp. 101-128). Barcelona: Paidos.

Mèlich, Joan Carles. (1994). Del extraño al cómplice. La educación en la vida cotidiana. Barcelona: Editorial Antropos.

Ortega, Pedro. (2004). Moral education as pedagogy of alterity. Journal of Moral Education, 33(3). DOI http://dx.doi.org/10.1080/0305724042000733055

Pérez, Pablo y Núñez Vladimir. (2008). Cuando el espacio se vuelve lenguaje: territorios, nación e identidades en las ciencias sociales. Signo y Pensamiento, 27(53), 16-21. Recuperado de http://www.redalyc.org/pdf/860/86011529001.pdf

Ricoeur, Paul. (1993). Amor y Justicia. Madrid: Caparros editores. 
Ricoeur, Paul. (1999). Historia y Narratividad. Barcelona: Paidós.

Ricoeur, Paul. (2000). Narratividad, fenomenología y hermenéutica. Revista Análisis, (25), 189-207. Recuperado http://www.raco.cat/index.php/analisi/article/viewFile/15057/14898

Ricoeur, Paul. (2002). Del texto a la acción. Ensayos de hermenéutica II. México: Fondo de cultura económica.

Ricoeur, Paul. (2004). Tiempo y Narración: Configuración del tiempo en el relato histórico. México D.F.: Siglo XXI editores.

Ricoeur, Paul. (2006). Sí mismo como otro. Madrid: Siglo XXI editores.

Schütz, Alfred. (1972). La construcción significativa del mundo social: introducción a la sociología comprensiva. Barcelona: Paidós.

Schütz, Alfred. (1974). El problema de la realidad social. Buenos Aires: Amorrortu Editores.

Simmel, George. (1927). Sociología: Estudios sobre las formas de socialización. Madrid: Revista de Occidente.

Skliar, Carlos. (2002). ¿Y si el otro no estuviera ahí? notas para una pedagogía (improbable) de la diferencia. Madrid: Miño y Dávila editores.

Skliar, Carlos. (2006). Fragmentos de amorosidad y de alteridad en educación. Revista Colombiana de Educación, (50), 253-266. Recuperado de: http://www.redalyc.org/articulo.oa?id=413635244014

Tuan, Yi Fu. (2007). Topofilia. Un estudio de las percepciones, actitudes y valores sobre el entorno. Madrid: Editorial Melusina.

Valera-Villegas, Gregorio. (2002). Pedagogía de la alteridad: una dialógica del encuentro con el otro. Venezuela: Fondo editorial humanidades

Van Manen, Max. (2003). Investigación educativa y experiencia vivida. Ciencia Humana para una pedagogía de la acción y la sensibilidad. Barcelona: Idea Books S.A.

Vázquez, Belín y Pérez, César (2009). Nuevas identidades - otras ciudadanías. Revista de Ciencias Sociales, 15(4), 653-667. Recuperado de http://www.redalyc.org/articulo.oa?id=28012285007

Vila, Eduardo. (2005). Ética, interculturalidad y educación democrática. Hacia una pedagogía de la alteridad. Huelva: Editorial Hergué. 